\title{
OIL LOSSES PADA FIBRE FROM PRESS CAKE DI PT. AMP PLANTATION UNIT POM
}

\author{
Kushisa Atta Jaeba ${ }^{1}$, Ega Tridiah Lestari ${ }^{2}$, Muhammad Ilham Adelino ${ }^{3}$ \\ ${ }^{1}$ Fakultas Teknik, Universitas Putra Indonesia "YPTK", Padang \\ email: kushiha_atta@upiyptk.ac.id \\ ${ }^{2}$ Fakultas Teknik, Universitas Putra Indonesia "YPTK", Padang \\ email: lestariegatridiah@gmail.com \\ ${ }^{3}$ Fakultas Teknik, Universitas Putra Indonesia "YPTK", Padang \\ email: milhamadelino@gmail.com
}

\begin{abstract}
PT. AMP Plantation Unit POM, which is a company that processes fresh fruit bunches which are located in Tapian Kandis village, precisely in Agam district, located in West Sumatra Province. The press process is an important stage in the production stage to obtain CPO. This process separates the oil from the pulp, fiber and nuts with quality standard control based on oil losses. The results of the percentage of several oil loss parameters on 20 July19 September 2020 show that fiber from press cake has the highest percentage, namely $38.01 \%$, while the lowest parameter percentage is shell of nut from press cake, namely $2.84 \%$. Therefore action is needed from the company in minimizing the occurrence of oil losses in fibre from press cake, laboratory analysts need to check every 2 hours using the Nir foss tool. The state of the pressing station. some of the actions taken by the pressing operator are checking the Digester, checking electrical panel, checking the Screw Press and making sure the sterilizer operator how long it takes to boil the fresh fruit bunches.
\end{abstract}

Keywords: Fresh Fruit Bunches, CPO, Percentage Of Fiber From Press Cake, Oil Losses

\begin{abstract}
Abstrak
PT.AMP Plantation Unit POM yang merupakan salah satu perusahaan dalam mengolah tandan buah segar yang berada di Desa Tapian Kandis, Kabupaten Agam, Sumatra Barat. Proses press, merupakan tahapan penting didalam tahapan produksi untuk memperoleh CPO. Proses ini memisahkan minyak dari daging buah, fibre dan nut dengan pengendalian standar kualitas berdasarkan oil losses. Hasil persentase beberapa parameter oil losses pada $20 \mathrm{Juli}-$ 19 September 2020 memperlihatkan bahwa fibre from press cake memiliki persentase paling tinggi yaitu 38,01\% sedangkan persentase parameter paling rendah adalah shell of nut from press cake yaitu $2,84 \%$. Oleh karena itu diperlukannya tindakan dari perusahaan dalam meminimalisir terjadinya oil losses pada fibre from press cake yaitu untuk analis laboratorium akan melakukan pengecekan setiap 2 jam sekali dengan menggunakan alat Nir Foss. Beberapa tindakan yang dilakukan operator pressing adalah memeriksa Digester, memeriksa panel elektrik, memeriksa Screw Press dan memastikan ke operator sterilizer lama perebusan tandan buah segar.
\end{abstract}

Kata kunci: Tandan buah segar, CPO, Persentase Fibre From Press cake, Oil Losses.

\section{PENDAHULUAN}

PT.AMP (Agra Masang Perkasa) Plantation Unit POM (Palm Oil Mill) adalah salah satu perusahaan yang mengolah tandan buah segar di Desa Tapian Kandis, Kabupaten Agam, Sumatra Barat. Perusahaan ini bergerak dalam bidang produksi dalam pengelolaan Crude Palm Oil (CPO) dan Palm Kernel (PK), 
dimana Crude Palm Oil (CPO) merupakan hasil olahan daging buah kelapa sawit melalui proses perebusan tandan buah segar, perontokan, penekanan dan pemurnian minyak. Sedangkan Palm Kernel (PK) merupakan hasil olahan dari inti sawit yang telah dipecah menjadi kernel.

Dalam mengolah tandan buah segar menjadi Crude Palm Oil PT. AMP Plantation Unit POM menggunakan permesinan yang sudah modern untuk menunjang proses produksinya. Diantara mesin-mesin yang ada di PT. AMP Plantation Unit POM terdapat salah satu mesin yang vital peranannya dalam pengolahan minyak kelapa sawit yaitu pada mesin press yang berfungsi untuk mengeluarkan minyak dari daging buah, selain itu mesin press juga dapat memisahkan minyak tersebut dengan fibre dan nut. Pada mesin press hasil untuk fibre itu tidak boleh terlalu basah dan tidak boleh terlalu kering, karena jika fibre terlalu basah maka akan mengakibatkan oil losses yang tinggi sedangkan jika terlalu kering maka akan terjadi broken nut. Salah satu permasalahan yang dihadapi oleh perusahaan yaitu tingginya oil losses fibre pada mesin press dimana ditemukannya fibre yang terlalu basah saat proses produksi berjalan. Jika proses produksi dapat berjalan dengan lancar maka perusahaan dapat menghasilkan CPO sebanyak 75 ton/jam, tetapi jika oil losses meningkat dan tidak dapat dikendalikan maka hal ini akan mengakibatkan kerugian bagi perusahaan.

PT. AMP Plantation Unit POM setiap parameter losses memiliki target dan jadwal pengecekan setiap 2 jam sekali pada saat proses produksi berlangsung, sehingga ketika ditemukan fibre yang terlalu basah pada mesin press maka dilakukan pengendalian dari operator analis lab dan operator pada stasiun pressing untuk meminimalisir terjadinya oil losses yang berkelanjutan. Target oil losses to FFB (Fruit Fresh Bunches) pada fibre adalah $\leq 0,48$. Berdasarkan data oil losses dari periode 20 Juli-19 September 2020, terdapat beberapa periode yang melewati batas yaitu sebanyak 10 periode dengan oil losses fibre yang terbesar adalah pada periode 21 Juli 2020 yaitu 0,508 dan untuk oil losses terkecil adalah pada periode 19 Agustus 2020 yaitu 0,399. Sedangkan untuk target oil losses on sample pada fibre sampel basah adalah $<$ 4,40\%. Dari data oil losses on sample periode 20 Juli-19 September 2020 terdapat beberapa oil losses on sample yang melewati target dengan losses terbesar pada periode 7 Agustus 2020 yaitu 5,98 pada jam 18.00 dan untuk oil losses terkecil adalah pada periode 26 Agustus 2020 yaitu 2,19 pada jam 16.00. Untuk mencapai target produksi yang telah ditetapkan, perusahaan perlu memastikan bahwa oil losses over limit pada fibre tetap berada pada batas yang telah ditetapkan.

Salah satu sistem manajemen yang diterapkan untuk mendapatkan jumlah rendemen yang optimal adalah menekan terjadinya kehilangan minyak (oil losses) pada CPO dan PKO selama proses produksi. Rendemen memiliki hubungan yang erat dengan kehilangan (losses), dimana jika losses rendah maka rendemen akan mengalami kenaikan. Losses minyak sangat dipengaruhi oleh proses pengolahan dimulai dari perebusan sampai klarifikasi. Proses pengolahan minyak kelapa sawit tidak terlepas dari oil losses. Untuk menurunkan kadar minyak dalam ampas tekanan dinaikan dengan mengatur cone. Tekanan yang terlalu tinggi akan mengakibatkan persentase biji pecah tinggi serta dapat merusak screw press sedangkan jika tekanan rendah akan menyebabkan persentase biji rendah tetapi minyak akan banyak terbuang. Oleh karena itu tekanan pada press harus stabil. 


\section{METODE PENELITIAN}

\subsection{Studi Literatur dan Survey}

Studi literatur dilakukan untuk mengetahui teori terkait penelitian berupa sawit, proses pengolahan sawit, analisis statistik dan konsep pemeliharaan mesin. Survey dilakukan untuk mengamati langsung proses produksi dilapangan, serta tahapan didalam pengumpulan sampel yang akan digunakan dalam penelitian ini.

\subsection{Pengumpulan Data}

Data diperoleh dari hasil sampling yang dilakukan oleh operator laboratorium dari terhadap hasil press masing-masing screw pada mesin press. Pengumpulan data dilakukan pada tanggal 20 Juli -19 September 2020.

\subsection{Sampel}

Tahap awal dilakukan dengan mengambil 6 sampel menggunakan plastic $1 \mathrm{~kg}$ berukuran $15 \mathrm{~cm}$ x $30 \mathrm{~cm}$. sampel yang telah diambil pada stasiun mesin press dibawa ke laboratorium untuk dilakukan sortasi nut dan ekstraksi losses minyak. Standar yang ditetapkan untuk losses minyak pada stasiun Press ini adalah sekitar 3,6\% untuk oil losses pada serat dan maksimal $18 \%$ untuk broken nut. Analisis dilakukan setelah proses produksi selesai, yaitu pada pagi hari dengan metode ekstraksi menggunakan pelarut n-heksan dengan mengambil sampel sebanyak lebih kurang 10 gram dan diekstraksi selama lebih kurang 6 jam untuk mengetahui oil losses. Untuk broken nut dilakukan dengan cara sortasi.

\subsection{Pengolahan dan Analisis}

Data hasil sampling analisis oleh operator laboratorium akan diolah untuk mengetahui oil losses terbesar dari parameter yang digunakan oleh perusahaan yaitu EB.Stalk, Fibre From Press Cake, Shell Of Nut from Press Cake, Effluent dan Solid. Selanjutnya analisis dilakukan terhadap parameter dengan losses terbesar berdasarkan peta kendali.

\section{HASIL DAN PEMBAHASAN}

\subsection{Analisis Oil Losses}

Analisis dilakukan menggunakan diagram pareto untuk melihat oil losses terbesar yang akan diolah dan dianalisis. oil losses tertinggi terdapat pada Fibre From Press Cake. Sedangkan untuk oil losses pada Effluent berada pada tingkat $\mathrm{Ke}-2$, selanjutnya EB.Stalk berada pada tingkat ke-3 sedangkan solid berada pada tingkat ke-4 dan untuk oil losses paling rendah terdapat pada Shell Of Nut From Press Cake. Oil losses tertinggi sering terjadi pada fibre di stasiun Pressing. Stasiun Pressing merupakan proses penekanan buah sawit menjadi minyak mentah, jika operator mengatur mesin press dengan tekanan tinggi maka akan terjadi nut losses pada press cake, jika tekanan terlalu rendah maka akan terjadi oil losses pada press cake. Untuk oil losses pada fibre dapat terlihat pada serabut atau fibre yang basah sehingga kemungkinan besar terjadinya kesalahan baik mesin, operator maupun bahan baku yang harus cepat diatasi.

\subsection{Analisis Peta Kendali}

Berdasarkan data pengamatan, untuk $E B$ Stalk, Shell of Nut From Press Cake dan Effluent tidak ada yang melewati target, untuk Solid terdapat 4 periode yang melewati target yaitu tanggal 24 Agustus 2020, 1, 12 dan 15 September 2020 dan untuk parameter yang sering melewati target yaitu pada parameter Fibre From Press Cake. Terdapat beberapa kali terjadinya over limit yaitu terlihat pada tanggal 20, 21, 28, 29, 30 Juli 2020 dan 4, 8, 21, 22 Agustus 2020 serta 16 September 2020. Sedangkan oil losses tertinggi pada parameter Fibre From Press Cake adalah periode 21 Juli 2020 yaitu 0,508 dan yang terendah pada periode 19 Agustus 2020 yaitu 0,399. Untuk peta kendali pada Stalk, Effluent, Nut from press cake, fiber from press cake, dan solid dapat dilihat pada gambar 1-5. 


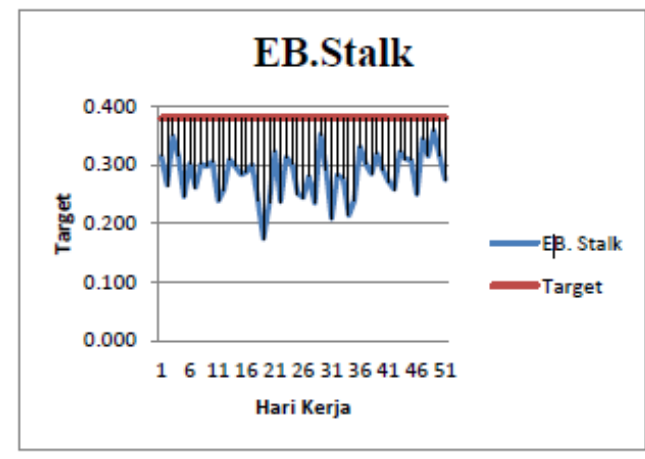

Gambar 1. Peta Kendali Oil Losses EB.Stalk

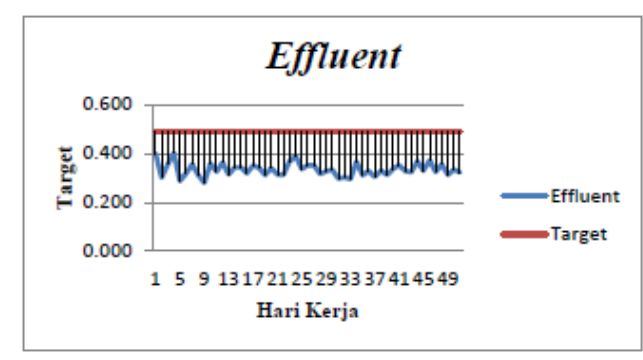

Gambar 2. Peta Kendali Oil Losses Effluent

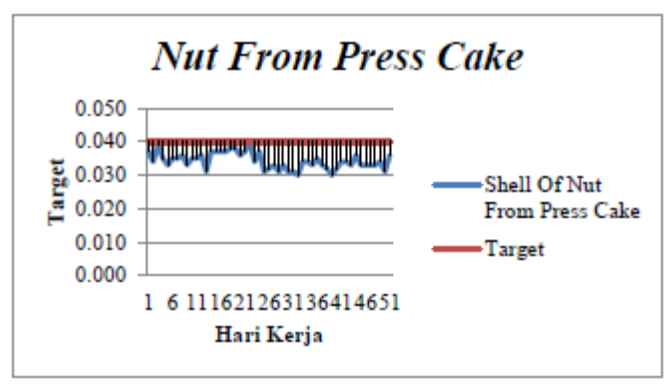

Gambar 3. Peta Kendali Oil Losses Nut From Press Cake

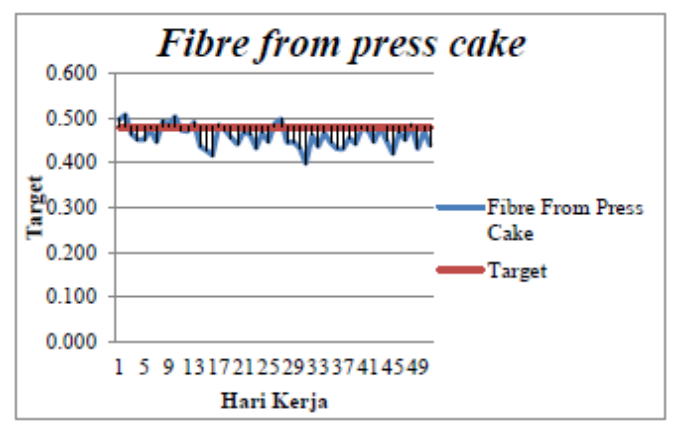

Gambar 4. Peta Kendali Oil Losses Fibre From Press Cake

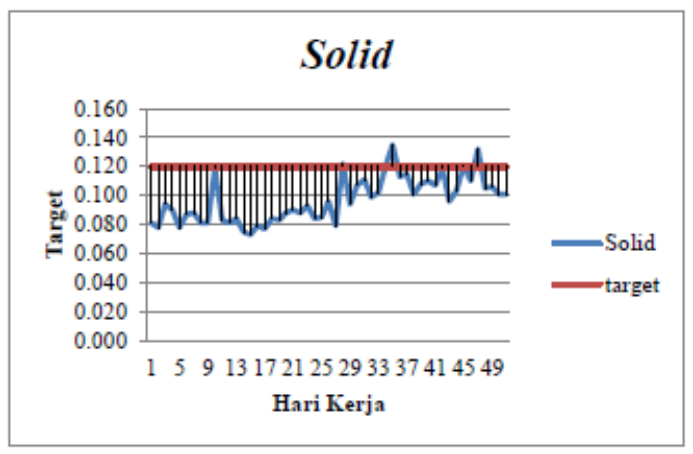

Gambar 5. Peta Kendali Oil Losses Solid

3.3. Identifikasi dan Penanganan Penyebab Oil Losses

Beberapa faktor terjadinya oil losses pada stasiun pressing antara lain Screw pada mesin press yang telah melewati umurnya akan mengakibatkan keausan pada screw sehingga juga dapat menyebabkan Screw patah, pada mesin Digester tidak boleh terjadi kekosongan umpan mesin press jika proses produksi masih berjalan, karena dapat menyebabkan oil loss over limit, Steam yang dimasukkan pada Digester mengalami penurunan, Pada mesin Digester harus diperhatikan, karena jika minyak sudah numpuk pada saringan Digester maka akan menyebabkan oil losses yang tinggi karena minyak terperangkap didalam Digester, dan Oil losses dapat juga terjadi karena buah yang mengkal dan buah yang belum masak pada stasiun sterilizer.

Dari beberapa penyebab terjadinya oil losses, perusahaan berusaha mengambil tindakan untuk meminimalisir terjadinya oil losses, berikut ini tindakan yang dapat dilakukan pada stasiun berdasarkan analisis menggunakan pendekatan perawatan. Pertama, suhu pada Digester harus dipertahankan $90-96^{\circ} \mathrm{C}$, jika tidak maka kerja Digester tidak akan berjalan dengan baik, jika suhu terlalu rendah maka dapat menyebabkan minyak akan sulit keluar dari fibre karena panas merupakan hal yang dapat mempercepat terlepasnya minyak dari fibre, sedangkan jika terlalu tinggi akan menyebabkan press akan basah karena steam lebih cenderung menjadi air, 
apabila bergabung dengan fibre maka fibre yang keluar dari pressan akan membawa air dan minyak. Kedua, untuk tekanan hidrolik harus dipertahankan 39-40 bar, jika dibawah 39 bar maka fibre akan basah dan akan menyebabkan losses yang tinggi sedangkan jika diatas 41 bar maka nut akan pecah.

Ketiga, untuk kuat arus pada Digester harus dipertahankan 25-30 Ampere, karena jika diatas 30 ampere maka elektromotornya akan terbakar, jika dibawah 25 ampere maka Screw Press tidak sanggup menerima fibre dan nut yang diberikan oleh Digester karena putarannya terlalu lambat. Keempat, kuat arus pada Screw Press dipertahankan 4045 ampere, Screw Press ini hanya bertahan selama 800 jam, jika lebih dari 800 jam dilakukan pergantian screw agar dapat menghindari keausan pada screw. Kelima, jika fibre sudah basah maka Digester akan didrain, kemudian minyak yang terdapat dalam Digester akan dialirkan ke Oil Gutter.

Keenam, setelah itu jika tidak ada lagi kesalahan pada mesin Press maka operator press akan memeriksa panel elektrik untuk melihat tekanan pada screw. jika rendah maka terjadi kesalahan pada perebusan. Ketujuh, untuk perebusan harus dilakukan pada suhu $120-130^{\circ} \mathrm{C}$, jika suhu dibawah $120^{\circ} \mathrm{C}$ maka pada Digester akan sulit terlepas dari nut sehingga jika dilakukan penggepresan dapat menyebabkan losses nya tinggi, sedangkan jika lebih dari $130^{\circ} \mathrm{C}$ maka buah akan terlalu lembek.

\section{SIMPULAN}

Oil Losses yang sering terjadi yaitu pada parameter Fibre From Press Cake, dengan beberapa kali terjadinya over limit. Penyebab oil losses pada mesin press diakibatkan oleh umur screw yang dipergunakan telah melewati masa pakai. Input bahan pada mesin press dari disgester sering terputus pada proses produksi, input steam pada disgester yang tinggi menyebabkan terjadinya penumpukan air pada bahan yang menyebabkan campuran air dan minyak semakin tinggi dan adanya bahan baku yang belum matang digunakan pada proses produksi. Perusahaan perlu melakukan penggantian komponen mesin secara berkala menggunakan spesifikasi yang sesuai untuk mencegah kerusakan komponen sebelum umur pakai tercapai. Perlu untuk memastikan SOP dan pengaturan standar mesin dipergunakan pada setiap tahapan proses untuk mencegah terjadinya kerusakan mesin disaat proses produksi berlangsung.

\section{DAFTAR PUSTAKA}

[1] Nugroho, A., \& Mangkurat, U. L. (2019). Buku Teknologi Agroindustri Kelapa Sawit.Banjarmasin: Lambung Mangkurat University Press

[2] Muhibuddin, O. A. (2014). Budidaya Kelapa Sawit dan Teknik Pengendalian Hama Tikus.Universitas Brawijaya.

[3] Dylan Trotsek.(2017). In Journal of Chemical Information and Modeling.Yogyakarta : CV Budi Utama.

[4] Panagiotis Tsarouhas, (2007),"Implementation of total productive maintenance in food industry: a case study", Journal of Quality in Maintenance Engineering, Vol. 13 Iss: 1 pp. $5-18$

[5] Davis, Roy. (1995). Productivity Improvements Through TPM : The Philosophy and Application of Total Productive Maintenance. Englewood Cliffs : Prentice Hall, Inc.

[6] Campbell, John D. dan Andrew K.S.Jardine. (2001). Maintenance Excellence : Optimizing Equipment Life-Cycle Decisions. New York : Marcel Dekker Inc.

[7] Walpole, R.E. (1995). Pengantar Statistika edisi ke-4. Jakarta : PT Gramedia. 
[8] Campbell, John D. dan Andrew K.S.Jardine. (2001). Maintenance Excellence : Optimizing Equipment Life-Cycle Decisions. New York : Marcel Dekker Inc.

[9] Ramakumar,R. (1993). Engineering Reliability : Fundamentals and
Applications. Englewood Cliffs : Prentice Hall International, Inc.

[10] Mobley. R.K., L.R. Higgins and D.J. Wikoff. 2008. Maintenance Engineering Handbook $7^{\text {th }}$ Edition. New York: McGraw-Hill 